IZA DP No. 6317

Why Are So Many Disabled Individuals Not Working in Spain? A Job Search Approach

Jose I. Silva

Judit Vall-Castello

January 2012 


\title{
Why Are So Many Disabled Individuals Not Working in Spain? A Job Search Approach
}

\author{
Jose I. Silva \\ Universitat de Girona \\ Judit Vall-Castello \\ Universitat de Girona, \\ Universitat Pompeu Fabra and IZA \\ Discussion Paper No. 6317 \\ January 2012 \\ IZA \\ P.O. Box 7240 \\ 53072 Bonn \\ Germany \\ Phone: +49-228-3894-0 \\ Fax: +49-228-3894-180 \\ E-mail: iza@iza.org
}

Any opinions expressed here are those of the author(s) and not those of IZA. Research published in this series may include views on policy, but the institute itself takes no institutional policy positions.

The Institute for the Study of Labor (IZA) in Bonn is a local and virtual international research center and a place of communication between science, politics and business. IZA is an independent nonprofit organization supported by Deutsche Post Foundation. The center is associated with the University of Bonn and offers a stimulating research environment through its international network, workshops and conferences, data service, project support, research visits and doctoral program. IZA engages in (i) original and internationally competitive research in all fields of labor economics, (ii) development of policy concepts, and (iii) dissemination of research results and concepts to the interested public.

IZA Discussion Papers often represent preliminary work and are circulated to encourage discussion. Citation of such a paper should account for its provisional character. A revised version may be available directly from the author. 


\section{ABSTRACT}

\section{Why Are So Many Disabled Individuals Not Working in Spain? A Job Search Approach*}

Unlike other disability systems in developed economies, the Spanish system allows partially disabled individuals to work while receiving disability benefits. The puzzle is, however, that employment rates in this group of individuals are very low. The aim of this paper is to understand the incentives and disincentives to work provided by the partial disability scheme in Spain. We first present a theoretical job search model for partially disabled individuals and then estimate a complementary log-log duration model. According to both models, the probability of finding a job falls with the level of disability, the age at which the individual starts receiving disability benefits, and the increase in the local unemployment rate. Moreover, as a result of an increase in the level of disability benefits we find a strong substitution effect that reduces the probability of disabled individuals older than 55 years finding a job to almost zero, in both of the two models. We simulate that the strong substitution effect would be replaced by an equally large income effect even if the increase in the benefits would not be suspended if the individual finds a job.

JEL Classification: $\quad$ C41, I18, J64

Keywords: disability benefits, job search model, duration analysis

Corresponding author:

Judit Vall-Castello

Departament d'Economia

Universitat de Girona

Campus de Montilivi

17071 Girona

Spain

E-mail: judit.vall@udg.edu

\footnotetext{
* We thank Nicolas Boccard, Maria Cervini and Manuel Toledo for helpful comments. We are grateful to the Spanish Ministry of Science and Innovation for financial support through grants ECO2009-07636.
} 


\section{Introduction}

In recent years, disability policies have attracted particular attention in OECD countries for two main reasons: because they represent an important source of government expenditure and because societies are becoming more and more concerned about the need to strengthen the integration of disabled individuals in society.

At the same time, several studies and organizations of people with disabilities have stressed the need to promote the labor market integration of disabled individuals as a way of facilitating their broader integration into society. The pre-conception that disability does not allow the individual to work in any kind of job is totally unfounded and some effort should be made in order to analyze how their abilities can be matched with employment opportunities (OECD, 2003).

For these reasons, the possibility of increasing the number of disabled people that work is regarded as a good way of decreasing the pressures on the financial stability of the social security system as well as achieving the social integration of disabled individuals. As the OECD puts it: "Helping (disabled) people to work is potentially a "win-win" policy: it helps people avoid exclusion and have higher incomes while raising the prospect of more effective labor supply and higher economic output in the long term" (OECD, 2007).

The promotion of the employment of disabled individuals is particularly relevant for the Spanish case and, in 2007, the OECD identified it as the most "formidable" challenge facing the Spanish government with respect to disability policies. Employment rates of self-reported disabled individuals in Spain have remained quite low at 30\% even though GDP growth has been quite high at around 2-6\% between 1996 and 2007. ${ }^{1}$ This is one of the lowest rates in the OECD, where employment rates for self-reported disabled individuals are $45 \%$ in the UK, $40 \%$ in Australia, 50\% in Luxembourg, $45 \%$ in Norway and $52 \%$ in Switzerland (see Figure 1). The situation becomes worse if, instead of considering self-reported disabled individuals, we calculate employment rates of individuals receiving partial disability benefits in Spain. We can see in Figure 2 that, for this group of individuals, the total employment rate is $17 \%$, much lower than the selfreported group (30\%). Figure 2 also shows that the employment rate for the oldest part of the disabled population is $6 \%$ (age $55-65){ }^{2}$

Therefore, the aim of this paper is to understand the incentives and disincentives to work provided by the partial disability scheme in Spain from the point of view of the individual and to identify the time until a job is found and the characteristics associated with the probability of finding a job for individuals in the disability rolls. When studying these issues, an important role will be played by the different degrees of disability pension available in the Spanish system that entail different working restrictions as well as amounts. The interplay between these types of pension and the rules and restrictions embedded in the legislation will prove to be key determinants of

\footnotetext{
${ }^{1}$ The general employment rate increased by $7 \%$ between 2001 and 2007 . In turn, $3.5 \%$ of the Spanish population is receiving disability benefits.

2 This group of workers represents almost half of the observations in our sample. This drop in employment is the result of a drop in participation rates from 34.6 for individuals below age 55 to 9.6 for individuals aged 55 or more.
} 
individual employment status decisions. Of course, individual characteristics, the labor market and economic conditions will also play a role in individual decisions. The ultimate aim is to draw some conclusions on the types of policy initiative that could be most effective in increasing the individual incentives to work for the group of partially disabled workers. ${ }^{3}$

Figure 1. Employment rates of working-age people with and without disability, latest available years (percentage).

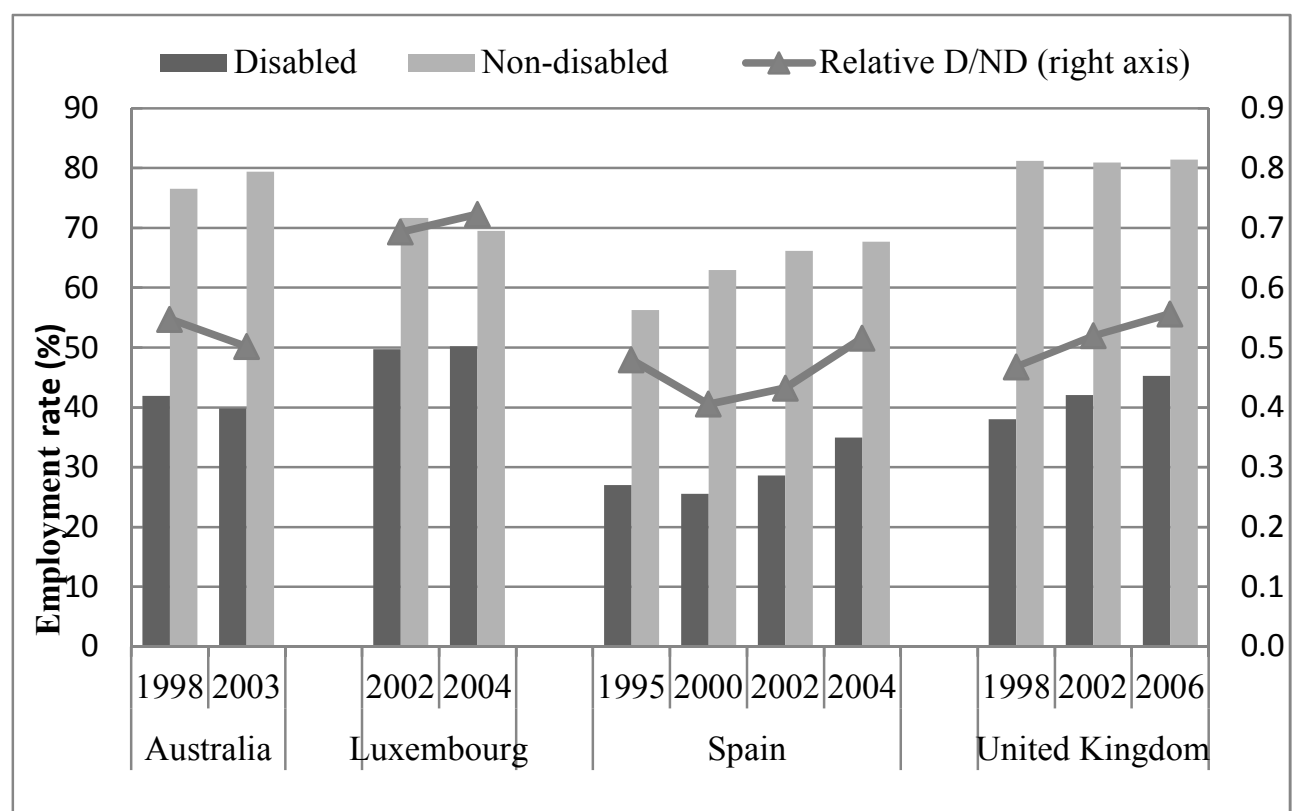

Definition of disability on self-assessment basis: existence of chronic health problem and long-term limitations on everyday activities.

Taken from OECD 2007. Source: SDAC (Australia); national labour force surveys (Luxembourg and Spain, 2002; United Kingdom); ECHP (Spain 1995, 2000); and EU-SILC (Luxembourg and Spain 2004).

The impact of disability regulations on the employment of disabled individuals has been documented in a recent book by Burkhauser and Daly (2011) and in several papers for the case of the USA (Autor and Duggan 2006, 2007, 2008; Autor et al. 2011; BenitezSilva and Heiland 2007, 2008). For the main Social Security Disability Insurance (SSDI) program in the USA, there seems to be common agreement among researchers that disability program rules and, in particular, the work-contingent basis of this program, have been the main explanation for the reported decline in the employment rates of individuals with disabilities through a substitution effect. That is, individuals stop working in order to access disability benefits even though they still have some capacity to work, because being able to prove the inability to work is a pre-condition to receiving the benefits. On the other hand, for an alternative disability program that is not contingent on the working status of the individual, the Veterans Administration's Disability Compensation (DC), Autor et al. (2010) and Boyle and Lahey (2010) also find significant evidence of decreases in labor supply as a result of an increase in benefits or an expansion in health insurance availability. However, in this case, this drop in labor supply cannot be interpreted as a substitution effect as access to this type

\footnotetext{
3 Another related paper (Vall-Castello, 2011) analyzes the effects on employment rates of disabled women of an increase in the incentives (deductions in Social Security contributions) for employers that hire disabled women.
} 
of disability benefit is not contingent on the working status of the individual. Therefore, both papers provide the intuition that this behavioural response may be the result of a non-distortionary income effect as individual resources increase due to the increase in benefits. However, there is no formal model in these papers that provides evidence of the existence of this causal channel.

Figure 2. Employment rates by age group of individuals receiving disability benefits in Spain.

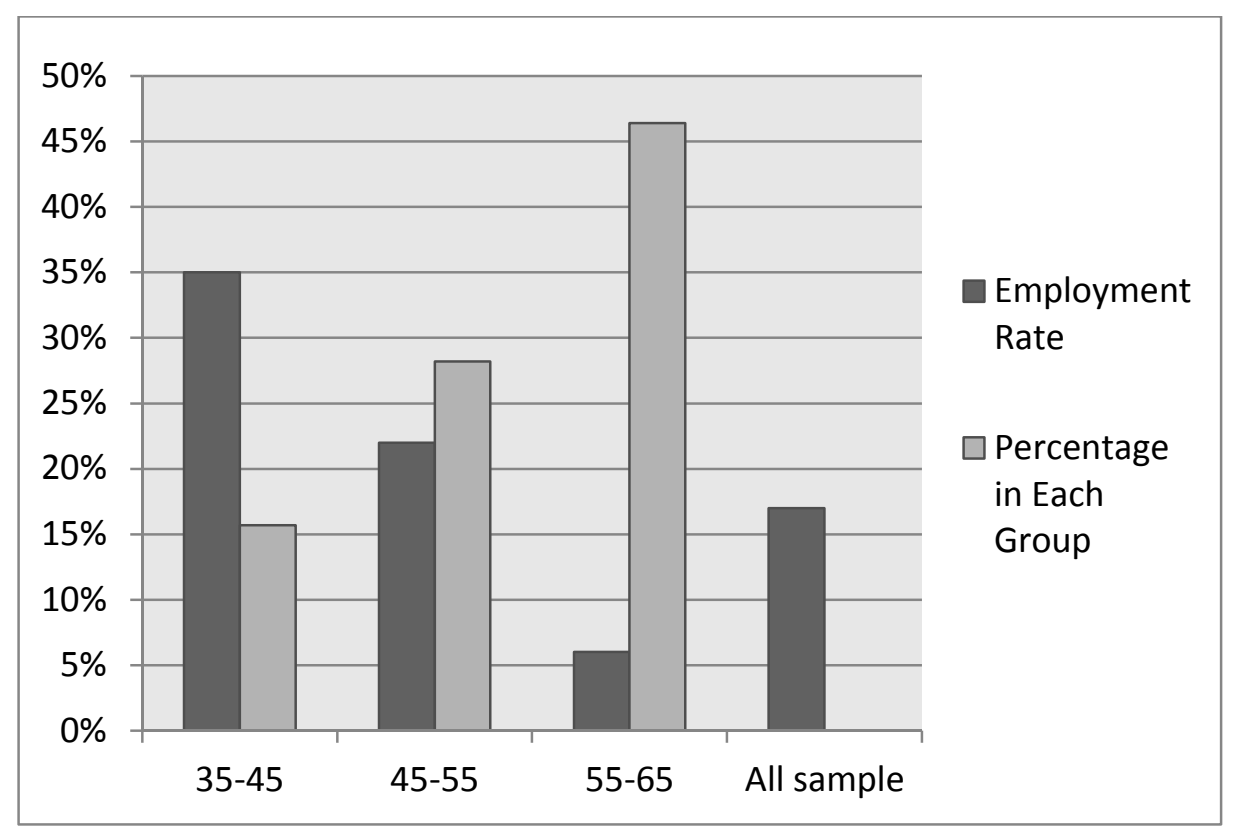

Employment rates of individuals receiving partial disability benefits in Spain.

Source: Continuous Sample of Working Lives ("Muestra Continua de Vidas Laborales", MCVL).

In this paper, we provide a formal model that allows us to understand the reasons behind the empirically observed drop in employment rates of partially disabled Spanish individuals that receive an increase in disability benefits. By contrasting the conclusions from the theoretical and the empirical models, we are able to distinguish between the substitution effect and other potential incentives embedded in the system. In order to do that, we first design a theoretical job search model with endogenous labor force participation to capture the incentives for partially disabled individuals to work and accept job offers. We derive some assumptions about the potential factors that could influence the probability of accepting a job. In particular, we assume that disability reduces the probability of finding a job because it both increases the probability of conversion to total disability and also reduces the job meeting probability with the employer due to the presence of higher searching costs. Moreover, disability increases the costs of working in a different job or professional activity. As a result, the reservation wage and, therefore, the probability of rejecting a job offer increases. We solve this model numerically to get some preliminary quantitative results. Then, we estimate a complementary log-log duration model with Spanish administrative data in order to test the predictions of the job search model. The predicted change in the hazard and job finding rates of the theoretical and the empirical model are very similar. According to both models, the probability of finding a job falls with the level of disability; the age at which the individual starts receiving disability benefits and the increase in the local unemployment rate. 
With respect to the policy implications, the Spanish system allows partially disabled individuals to receive an increase in benefits from $55 \%$ to $75 \%$ of the regulatory base if they are older than 55 and lack an education or training or are exposed to adverse social and labor market conditions. ${ }^{4}$ However, the legislation also states that if the individual begins working while receiving the $75 \%$, the $20 \%$ increase will be suspended until he stops working. To test the impact of this policy, in the empirical model we use age as an instrumental variable for receiving this increase in benefits and predict a large decrease in the annual hazard rate of finding a job of 13.5 percentage points. There are three potential explanations for this fall in the job finding rate: (i) a substitution effect as the increase in the benefits is suspended if the individual works (ii) a substitution effect due to the possibility of an increase in the personal income tax rate as the total income of the individual increases, or; (iii) an anticipation effect generated by the belief that not working would maximize the chances of being granted the increase in benefits. We use the theoretical model to explore the extent to which each of these explanations are responsible for the drop in employment. In the theoretical model, we observe that an increase in disability benefits from $55 \%$ to $75 \%$ of the regulatory base when the individual is not working affects the job finding rate for disabled individuals, which decreases by 14 percentage points as the reservation wage increases by $54 \%$. Moreover, the model simulates a reduction in the participation rate of the working age population from $34.6 \%$ to $17.0 \%$, which is somewhat similar to the rate observed in the data (from $34.6 \%$ to $9.6 \%$ ). Therefore, the results of our theoretical model together with the analysis of additional empirical evidence eliminate the possibility of any other nonwork incentive effect generated either by an increase in the marginal tax rate or by the presence of an anticipation effect.

Finally, we also perform a policy evaluation experiment with the theoretical model to test the employment effects of abolishing the working restriction of the $20 \%$ increase in the benefits. Our results show that even when the increase is not dependent on the employment situation of the individual, the job finding probability is reduced to virtually zero due to the presence of a strong income effect. Therefore, the large observed drop in employment due to the increase in the benefits would exist due to either a substitution or an income effect independently of the working restrictions embedded in the legislation.

To the best of our knowledge, there has been no previous attempt in the literature to model job search behaviour with matching frictions of disabled individuals. In our model, we incorporate the specificities that the disability condition and the receipt of disability benefits entail. Therefore, this is the first presentation of such a model and test of the predictions of this theoretical model with real data from the Spanish population. ${ }^{5}$ There are, however, a number of papers for the USA that model labour supply and disability as exclusive states (Benitez-Silva et al., 2011; Yin and Benitez-Silva, 2009).

\footnotetext{
${ }^{4}$ The disincentives to work of this particular policy have been estimated in the paper by Marie and VallCastello (2011). Using a regression discontinuity model, they find that the increase in benefits reduces employment probability by $8 \%$.

${ }^{5}$ There is, however, one exception by Buddelmeyer (2001) who has specified a job search model for the Dutch case. In this model, disability benefits are recalculated with job decisions. Thus, there is the possibility that accepting the job offer would mean losing all disability benefits. In our case, disability benefits are always operative. However, since the disabled cannot develop all of the fundamental tasks of their usual job we include the presence of assimilation costs for being in a different job or professional activity. Moreover, and unlike Buddelmeyer (2001), we include the presence of matching frictions and assume that there are probabilities of losing the job or becoming totally disabled.
} 
One of these papers (Benitez-Silva et al. 2011) uses a calibrated life-cycle model to prove that allowing for a new option of combining part of the disability benefits with a job (like in the Spanish system) would improve the welfare of disability recipients in the USA.

The paper proceeds as follows: section 2 describes the specificities of the Spanish system of disability benefits. Section 3 introduces the job search model that has been designed to capture the incentives that shape individual's decisions regarding employment status and some quantitative preliminary results are presented in section 4 . Section 5 explains the econometric approach used in the analysis and presents the complementary log-log model. Finally, the main results are summarized in section 6 and some conclusions are derived in the final part of the paper.

\section{The Spanish System: Are disabled individuals able to work?}

In Spain, permanent contributory disability pensions are defined as the economic benefits that aim to compensate the individual for losing a certain amount of wage or professional earnings. ${ }^{6}$ This happens when the person is affected by a reduction or a complete loss of his/her working ability in a way that is assumed to be permanent due to the effects of a pathologic or traumatic process derived from an illness or an accident. ${ }^{7}$

In order to capture the different situations in which a person can be after suffering from a disabling condition, the Spanish Social Security administration differentiates between three degrees of disability that depend on the amount of working capacity that has been lost: (i) permanent partial disability for the usual job (PD), which is the kind of impairment that prevents the individual from performing all or the fundamental tasks of his/her usual job or professional activity but the individual is still capable of doing a different job or professional activity; (ii) permanent total disability for all jobs (TD) for the kind of impairment that prevents the individual from performing any kind of job or professional activity and; (iii) severe disability where, as a result of anatomic or functional loses, the individual needs the assistance of a third person to do the most essential everyday actions, such as eating, moving, etc.

Therefore, the degree of disability with which the individual is classified is set in relation to the working capacity lost, and the amount of pension received varies according to the same. For example, individuals in the partial disability scheme receive, in general, $55 \%$ of the regulatory base (which is an average of their last salaries) because they are assumed to get some income from work that would earn them a similar amount of money to what they received before becoming disabled. This $55 \%$ can be increased to $75 \%$ for individuals aged 55 or more with lower skill levels and exposed to unfavorable local labor market conditions that are deemed to make it difficult for them to find employment. However, when defining the compatibilities of the receipt of this increase in the benefits, the legislation stresses that if the individual starts working

\footnotetext{
6 Please note that, for the purpose of this paper, we only focus on contributory pensions, which are economic benefits that require receivers to have contributed to Social Security before becoming disabled (employed or receiving unemployment benefits). The reasons for considering only the contributory part of the system are data availability problems for non-contributory pensioners and the idea that disabled individuals that have worked before are probably in a better position to find a new job.

7 Own translation of the definition of permanent disability given by the Spanish Social Security administration at www.seg-social.es.
} 
while receiving the $75 \%$, he will have to report it to the Social Security Administration and the $20 \%$ increase will be suspended until he stops working. On the contrary, total disability pensions provide $100 \%$ of the regulatory base as the individual is considered to have lost all his/her ability to work and is therefore unable to get any extra income from work.

Such disability schemes that acknowledge several degrees of disabling conditions and include in their definition the possibility of working while receiving a proportion of the total amount of benefits are labelled in the literature 'partial disability schemes' and, other than Spain, can also be found in a number of European countries, such as The Netherlands, Germany and Sweden.

The situation is very different in countries like the United States, where the disability insurance program is defined as an all-or-nothing system for which the disabled individual can only be eligible and receive full disability benefits if he/she is found to have suffered a complete loss of work capacity. The alternative to that entails receiving zero benefits and occurs when the individual is found to still have some capacity to work. It is widely recognized that this dichotomous definition of disability entails huge disincentives to work because partially disabled individuals that still have some ability to work but that have suffered from a loss of income due to the disabling condition might have incentives to apply for the disability scheme if their reduced wage does not allow them to make ends meet. ${ }^{8}$

Therefore, in systems with a binary definition of disability, the prohibition on working once the individual is on the disability rolls is imposed by the same definition of disability. ${ }^{9}$ Participation in the labor market would only be possible in the case of recovery from the disabling condition which would, in turn, entail losing the right to disability benefits (Benitez-Silva and Heiland, 2008; Maestas and Yin, 2008).

The puzzle that fosters this research lies in the observation that, even though partial disability pensioners in Spain are "legally" given the option to combine the disability pension with a job and even though they have received a medical examination that classifies them as "able to engage in a job", the data show that most of the disabled individuals in Spain are not working. For this paper, our interest lies in the incentives of disabled individuals to accept/reject a job and, for this reason, we are restricting our analysis to disabled individuals in the partial disability scheme.

\section{Theoretical job search model}

The economy consists of a continuum of infinitely-lived workers, $j$, with a partial disability who cannot perform any of the fundamental tasks of their usual jobs but are still capable of doing different jobs or professional activities. A disabled person can either be employed or non-employed. If he/she is not employed he/she may decide to

\footnotetext{
8 The recognition of the disincentives to work provided by the USA disability system are even acknowledged by the Social Security Advisory Board, see Yin (2010).

${ }^{9}$ For a complete analysis of the disincentives embedded in the USA disability insurance system see all the work by Benitez-Silva and Autor and Duggan (Benitez Silva and Heiland, 2007, 2008; Benitez-Silva et al, 2011, Autor and Duggan 2006, 2007, 2008). For a simulation of the effects of changing from the current binary disability definition in the USA to a partial definition, see Yin (2010).
} 
search for a job, and thus participate in the labor market as an unemployed worker, or not. The individual discounts future payoffs at a common rate $\beta$ and time is discrete. We assume the presence of a log-utility function for the consumption of each period of income. $^{10}$

Any disabled individual's status of partial disability may be converted to total disability with a probability,

$$
\rho(d i s)=d i s^{\kappa}
$$

where dis captures the degree of disability bounded between 0 and 1 and $\kappa>0$. In the case of total disability, the individual cannot work. With a degree of disability of $100 \%$, $d i s=1$, the probability of conversion to total disability is equal to one.

All individuals with partial disability receive a pension equivalent to a proportion, $\alpha$, of their average wage for the years previous to the accident or illness, $w_{0, j}$. When a disabled person is out of the labor force he/she enjoys a utility flow $h_{j}$ each period. The variable $h_{j}$ includes the imputed real return from any unpaid leisure activities such as home production and has to be given up when the disabled person decides to participate in the labor force. Similar to Pissarides (2002, chapter 7), home productivity differs across disabled individuals. Formally, we assume that $h_{j}$ is redrawn from a distribution with cumulative density $F\left(h_{j}\right)$. Individuals decide to look for a job if, for a given threshold level $h_{R}$, the present-discounted return of being out of the labor force, $I_{j}$, is lower than the present-discounted return of being unemployed, $U_{j}$. Formally, the participation rule is

$$
I_{j}\left(h_{R}\right)=U_{j}
$$

This rule implies that no individual will be willing to work for less than $U_{j}$. Moreover, an unemployed worker can withdraw from the labor market at any period and enjoy $h_{j}$. This happens when their home productivity $h_{j}$ exceeds $h_{R}$.

In searching for a job, all disabled individuals enjoy the same utility flow $b$, which includes unemployment benefits and some level of home production net of search costs. This employment opportunity cost has to be given up when the disabled person finds a job. Each period, and in the case of no conversion from partial to total disability with probability $1-\rho(d i s)$, an unemployed individual meets a firm with probability $\lambda(u, d i s)$. In particular, we assume a Cobb-Douglas aggregate meeting function of the form:

$$
\lambda(u, d i s)=\varphi_{1}(1-d i s) u^{-\varphi_{2}}
$$

with parameters $0<\varphi_{2}<1$ and $\varphi_{1}>0$. According to this equation, the higher the number of unemployed workers, $u$, the more difficult is to meet a firm for each disabled worker. Notice that, the meeting probability is also decreasing along with the level of disability, dis. Thus, it is more difficult for a person with a disability to find jobs than it is for a person without one. When the level of disability is $100 \%$, then dis $=1$ and, therefore,

\footnotetext{
${ }^{10}$ Similar to Postel-Vinay and Robin (2002), we rule out intertemporal transfers and saving and assume incomplete insurance markets.
} 
disabled individuals cannot look for jobs. In fact, according to equation (1), for $d i s=1$ the individual has a $100 \%$ probability of their status changing to total disability.

After the meeting, the worker receives a wage offer $w_{j}$ taken from the cumulative distribution function $G\left(w_{j}\right)$ with support $\left[0, w^{\max }\right]$. Unemployed workers decide to accept a job offer if, for a given reservation wage $w_{R, j}$ the present-discounted return of being unemployed, $U_{j}$, is lower than the present-discounted return of being employed, $L_{j}$,

$$
L_{j}\left(w_{R, j}\right)=U_{j}
$$

There is a constant flow cost of working for a disabled individual, $C$, which increases with the degree of disability, dis. $C$ also includes the assimilation costs for being in a different job or professional activity. We assume that the assimilation costs decrease with the previous job experience, exp, and increase with the age at which the individual becomes disabled. The $C$ function takes the following form:

$$
C(\text { dis, exp })=\operatorname{dis} \times e^{\delta_{1} \frac{\text { age }}{\exp }}
$$

Finally, disabled employees separate from their jobs with a constant probability $\gamma$ per period. Denoting the individual's value of being out of the labor force with partial disability as $I_{j}$ the workers' values of being unemployed and employed with partial disability as $U_{j}$ and $L_{j}$ respectively, and the value of a person with total disability as $A_{j}$, the following Bellman equations describe the model:

$$
\begin{gathered}
\left.I_{j}=h_{j}+\log \left[(1-\tau) \alpha_{I} w_{0, j}\right]+\rho(\text { dis }) \beta A_{j}+(1-\rho(\text { dis })) \beta I_{j}, \quad \text { (6) }\right) \\
U_{j}=b+\log \left[(1-\tau) \alpha_{U} w_{0, j}\right]+(1-\rho(\text { dis })) \beta\left\{\lambda ( u , d i s ) \left[\int_{w_{R, j}}^{w^{\max }} L_{j}\left(w_{j}\right) d G\left(w_{j}\right)+\right.\right. \\
\left.\left.G\left(w_{R, j}\right) U_{j}\right]+(1-\lambda(u, d i s)) U_{j}\right\}+\rho(\text { dis }) \beta A_{j}, \quad \text { (7) } \\
L_{j}=\log \left\{(1-\tau)\left[\alpha_{L} w_{0, j}+w_{j}\right]+\tau s-C(\text { dis, exp })\right\}+(1-\rho(\text { dis })) \beta\left\{\gamma U_{j}+\right. \\
\left.(1-\gamma) L_{j}\right\}+\rho(\text { dis }) \beta A_{j}, \quad \text { (8) } \\
A_{j}=h_{j}+\log \left(w_{0, j}\right)+\beta A_{j} .
\end{gathered}
$$

In equations (6) and (7), the second term of the RHS gives the net partial disability pension after taxes, $\tau$. In contrast, in the second term of equation (9), the individual receives the total disability pension and does not pay taxes. In turn, the first RHS expression in equation (8) corresponds to the net income after taxes, $\tau$, and deductions, $s$. According to equation (9), when an individual changes from partial to total disability, he/she remains in this status. This last assumption is consistent with the fact that, in Spain, only $1 \%$ of individuals with total disabled benefits change their status to partial disability.

The probability of unemployed individuals with partial disability finding jobs is: 


$$
f_{j}=(1-\rho(d i s)) \lambda(u, d i s)\left(1-G\left(w_{R, j}\right)\right) .
$$

For a given reservation wage, notice that the level of disability reduces the job finding probability because it both increases the conversion probability to total disability, $\rho(d i s)$, and reduces the job meeting probability with the employer, $\lambda\left(u_{t-1}, d i s\right)$. In turn, the average job finding probability is

$$
\bar{f}=\int_{h_{\text {min }}}^{h_{R}} f_{j} d F\left(h_{j} \mid h_{j} \leq h_{R}\right),
$$

where $F\left(h_{j} \mid h_{j} \leq h_{R}\right)=\frac{F\left(h_{j}\right)}{F\left(h_{R}\right)}$.

In the next section, we solve this model numerically to get some preliminary quantitative results with respect to the reservation wage and, therefore, the job finding rate for partially disabled individuals. Then, in section 5 , we estimate a complementary $\log -\log$ duration model with Spanish administrative data and compare the estimated results with the simulated ones from our theoretical model.

\section{Calibration and Simulations of the model}

In the first part of this section we parameterize the model for the average individual below 55 years of age $\left(^{*}\right)$, and for the average period 1996-2010, to be consistent with certain empirical Spanish labor market facts taken from the Continuous Sample of Working Lives ("Muestra Continua de Vidas Laborales", MCVL).

\subsection{Calibration}

The average age at which individuals become disabled is 44 with a discount factor of $\beta=0.96$, which implies a reasonable interest rate of nearly 4 percent. Using the Spanish data, we normalize the average wage, $w_{\text {mean }}=1$, and estimate a log-normal distribution with standard deviation, $\sigma_{w}=0.13$. The distribution function of home productivity $F\left(h_{j}\right)$ is also assumed to be log-normal. The reservation home productivity $\bar{h}_{R}^{*}$, is chosen to match the average participation rate of $34.6 \%$ for disabled individuals below 55 years of age. Thus, we set $F\left(h_{R}\right)=0.346$ and, in consequence, the home reservation productivity at $h_{R}=0.854$. In turn, a standard deviation of home productivity of $\sigma_{h}=0.40$ is set to match the average participation rate of $9.6 \%$ for disabled individuals above 55 years.

From the data, we set the conversion rate from partial to total disability and the unemployment rate at $\rho=0.015$ and $u=0.136$, respectively. Using the definition of partial disability and information from tax deductions, we assume that partial disability represents a reduction of between $33 \%$ and $65 \%$ of the working ability and set it at the average, dis $=0.50$. According to (1), it implies that $\kappa=6.059$. In turn, the average transition rate from state $L^{*}$ to $U^{*}$ is $\gamma=0.157$, while the average job finding rate during the period is $\bar{f}^{*}=0.140$.

The average wage for a disabled worker is 5,807 euros/year. If the individual works, there is a reduction of 2,800 euros/year in the employment income used to calculate income tax if the disability level is between $33 \%$ and $65 \%$. Since this amount represents 
$48.2 \%$ of the average wage for disabled workers, we set $s=0.482$. Using the OECD Tax Database, we take an average income tax of $15 \%, \tau=0.15$.

Individuals below 55 years of age in the partial disability scheme receive $55 \%$ of the regulatory base even if they work or not, (which is an average of the last eight years of salaries). In turn, the average regulatory base is 9,600 euros/year, which represents 1.65 times the average wage of a partially disabled worker. Thus, we set $\alpha_{I}=\alpha_{U}=\alpha_{L}=$ $\alpha=0.55$ and $w_{0}=1.65$. We calibrate the employment opportunity cost, $b$, to match the elasticity of unemployment duration with respect to the level of unemployment benefits to be equal to 1.83, which has been estimated by Addison, Centeno and Portugal (2004) for Spain. Thus, we set $b=0.278$.

Workers report an average of 19.2 years of job experience before they become disabled. Thus, we set $\exp =19.2$. The average age at which they become disabled is 44 . Thus, we fix age $=44 .{ }^{11}$ With respect to the elasticity of the meeting function, Petrongolo and Pissarides (2001) find the elasticity of the matching function with respect to unemployment to be in the range $0.5-0.7$. We choose an intermediate value and set $\varphi_{2}$ $=0.6$.

Since we do not have information on the working costs for a disabled individual, we approximate them by taking the difference between the labor income before receiving the disability pension and the average labor income that the disabled worker earns in their new job. In Spain, this gap is equivalent to $65 \%$ of the average wage of a disabled worker. Thus, we set $C=0.65$. Using equation (3), the level of disability and the work related experience we find the parameter $\delta_{1}$,

$$
\delta_{1}=\frac{\ln (C)-\ln (\text { dis })}{\frac{\text { age }}{\text { experience }}}=\frac{\ln (0.65)-\ln (0.50)}{\frac{44.0}{19.2}}=0.115
$$

Finally, the average values of $I^{*}, U^{*}, L^{*}$ and $A^{*}$, the average home productivity $\bar{h}^{*}$, the reservation wage $w^{*}$, the job meeting probability $\lambda(u *$, dis $)$ as well as its parameter $\varphi_{1}$, are calibrated by solving simultaneously equations (6)-(11) together with equations (2) and (4). Solving this system of equations yields $I^{*}=4.82, U^{*}=5.43, L^{*}=5.50$, $A^{*}=18.59, \bar{h}^{*}=0.243, w_{R}^{*}=0.918, \lambda(u$, dis $)=0.191$ and $\varphi_{1}=0.115$. Table 1 shows the calibrated values for the set of parameters and variables. Notice that with the calibrated reservation wage, the probability of rejecting a job offer is $G\left(w^{*}{ }_{R}\right)=0.256$, implying that most disabled individuals who want to work do not receive job offers. Along this line, the Survey of Disability, Personal Autonomy and Dependence ${ }^{12}$ database reports that 40 per cent of disabled individuals think they do not find jobs because of their disability.

\footnotetext{
${ }^{11}$ Remember that the standard deviation of home productivity of $\sigma_{h}=0.40$ is set to match the difference in the average participation rate of individuals below and above 55 years of age (34.6 versus 9.6).

${ }^{12}$ The Survey of Disability, Personal Autonomy and Dependence is a national survey that has been implemented three times (1986, 1999 and 2008) by the Spanish National Institute of Statistics.
} 
Table 1: Annual calibrated values for the average Spanish disabled individual. Period 1996-2010

\begin{tabular}{|c|c|c|}
\hline Parameters & Value & Definition \\
\hline$w^{*}$ mean & 1 & Normalization of average wage \\
\hline $\bar{h}^{*}$ & 0.243 & Average home productivity \\
\hline$\beta$ & 0.96 & Discount factor \\
\hline$\sigma_{w}$ & 0.13 & Standard deviation for the distribution of wages \\
\hline$\sigma_{h}$ & 0.40 & $\begin{array}{l}\text { Standard deviation for the distribution of home } \\
\text { productivity }\end{array}$ \\
\hline$b$ & 0.278 & Employment opportunity cost \\
\hline$\varphi_{2}$ & 0.6 & Matching function elasticity \\
\hline$\varphi_{1}$ & 0.115 & Matching function scale. \\
\hline$\rho$ & 0.015 & Conversion rate from partial to total disability \\
\hline$u$ & 0.136 & Average unemployment rate \\
\hline$s$ & 0.482 & Income deduction \\
\hline$\gamma$ & 0.157 & Job separation rate \\
\hline$\tau$ & 0.15 & Average income tax rate \\
\hline$w_{0}$ & 1.65 & Regulatory base for disability \\
\hline$\alpha$ & 0.55 & Partial disability scheme \\
\hline dis & 0.50 & Proportion of disability \\
\hline age & 44 & Average age \\
\hline $\exp$ & 1.22 & Average professional categories \\
\hline$\delta_{1}$ & 0.115 & Working costs parameter for a disabled individual \\
\hline$\kappa$ & 6.059 & Conversion parameter to total disability \\
\hline \multicolumn{3}{|l|}{ Variables } \\
\hline$w_{R}^{*}$ & 0.918 & Reservation wage \\
\hline $\bar{f}^{*}$ & 0.140 & Job finding rate \\
\hline$G\left(w_{R}^{*}\right)$ & 0.256 & Job rejection probability \\
\hline$F\left(h_{R}^{*}\right)$ & 0.346 & Participation rate \\
\hline$h_{R}^{*}$ & 0.854 & Home reservation productivity \\
\hline$I^{*}$ & 4.82 & $\begin{array}{l}\text { The present-discounted return of being out of the labor } \\
\text { force with partial disability }\end{array}$ \\
\hline$U^{*}$ & 5.43 & The present-discounted return of being unemployed \\
\hline$L^{*}$ & 5.50 & The present-discounted return of being employed \\
\hline$A^{*}$ & 18.59 & $\begin{array}{l}\text { The present-discounted return of being out of the labor } \\
\text { force with total disability }\end{array}$ \\
\hline
\end{tabular}




\subsection{Simulations}

In table 2 we present the results of a sensitivity analysis and compare them with the benchmark simulation. We present the results for some variables such as the reservation wage, $w^{*}$, the reservation home productivity, $h_{R}{ }_{R}$, the job rejection probability, $G\left(w^{*}{ }_{R}\right)$ , the participation rate, $F\left(h^{*}{ }_{R}\right)$ and the average employment probability, $\bar{f}^{*}$.

With respect to the aggregate labor market conditions, we observe that an increase in the unemployment rate of five percentage points (from 0.136 in the benchmark case to 0.186 ) reduces the average job finding probability by 1.8 percentage points (from 0.140 to 0.118 ). This negative effect is explained by a reduction in the job meeting probability $\lambda(u *$, dis $)$ from 0.191 to 0.158 . In contrast, the simulated reduction in the reservation wage from 0.918 to 0.913 increases the probability of accepting a job offer, (1 $G\left(w_{R}^{*}\right)$ ), and in consequence, the individual's job finding probability, $f$. We can also observe that the increase in unemployment generates a discouraged worker effect that decreases the participation rate from $34.6 \%$ to $32.8 \%$.

Figure 2: Simulated effects of disability
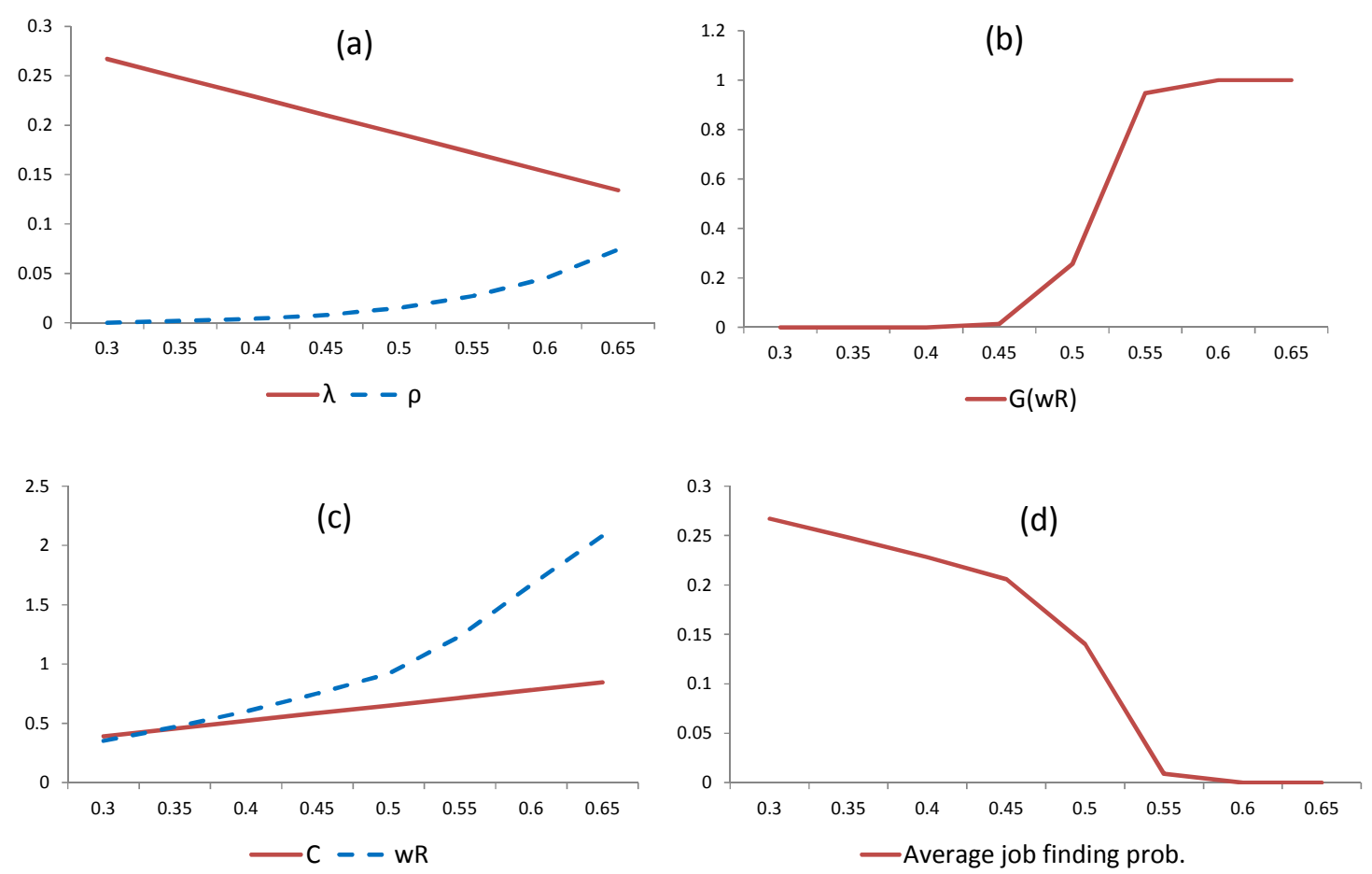

Regarding individual characteristics, Table 2 also shows that when the degree of disability increases from $50 \%$ to $65 \%$, the job finding probability falls to zero. To understand this result, Figures 2(a)-2(d) display, in more detail, how disability affects the job finding process. On the one hand, dis reduces the job meeting probability in Figure 2(a) because it becomes more difficult to search for jobs. Moreover, a higher degree of disability also increases the conversion probability from temporal to total disability, $\rho$, (see the dashed line in Figure 2(a)). According to equations (10)-(11), these two effects reduce the job finding probability (see Figure 2(d)). On the other hand, 
dis also increases the costs of working in a different job or professional activity, $C$, in Figure 2(c). As a result, the reservation wage, $w_{R}^{*}$, and the probability of rejecting a job offer, $G$, go up in Figures 2(c) and 2(b), respectively. With a higher $G$ the employment probability goes down. Notice that when the degree of disability is equal to or higher than $60 \%$, the assimilation costs are too high and the disabled individual does not work because the reservation wage is higher than the wage offer. In fact, disabled individuals decide to stay out of the labor force, $F\left(h^{*}{ }_{R}\right)=0$.

Continuing the sensitivity analysis with respect to the individual characteristics, Table 2 shows that an increase in the age of becoming partially disabled from 44 to 50 reduces the job finding probability from 0.140 to 0.094 . When a newly disabled individual is older, the job assimilation costs for being in a different job, $C$, are relatively higher. Thus, it becomes less attractive to work and, therefore, the reservation wage increases from 0.918 to 0.999 . As a result, the probability of rejecting a job offer increases and, therefore, the probability of finding a job falls. In this case, the labor force participation falls from $34.6 \%$ to $17.1 \%$. In contrast, since $C$ is reduced with job experience, exp, an increase in exp by one year increases the job finding probability by 1.2 percentage points.

Finally, with respect to the policy parameters, we observe that when the tax rate increases from $15 \%$ to $25 \%$, the probability of finding a job falls by 4.3 percentage points. In this case, the net labor income is reduced, increasing the reservation wage to 0.995 and, in consequence, the job rejection probability rises to $G\left(w_{R}\right)=0.485$. The opposite result occurs when the amount of tax deductions, $s$, is increased from $48 \%$ to $58 \%$ of the average wage. A final interesting result is the negative effect of partial disability benefits on the labor market adjustment. For example, the job finding probability falls to almost zero when the disabled individual receives $75 \%$ of the regulatory base, instead of $55 \%$ as in the benchmark case. This result is due to the presence of an income effect as in this simulation exercise the increase in the benefits is given without being conditioned on the working status of the individual. This effect reduces labor force participation from $34.6 \%$ to $16.7 \%$ and the job finding rate falls to practically zero.

Table 2: Simulated results for the sensitivity analysis

\begin{tabular}{|c|c|c|c|c|c|c|}
\hline Scenario & $w^{*}{ }_{R}$ & $h^{*}{ }_{R}$ & $G\left(w^{*}{ }_{R}\right)$ & $F\left(h^{*}{ }_{R}\right)$ & $\bar{f}^{*}$ & $\bar{f}^{*}-\bar{f}^{*}{ }_{\text {benchmark }}$ \\
\hline $\begin{array}{c}\text { Benchmark } \\
\text { scenario: }\end{array}$ & 0.918 & 0.854 & 0.195 & 0.346 & 0.140 & - \\
\hline $\begin{array}{c}\text { Aggregate } \\
\text { abor market } \\
\text { conditions }\end{array}$ & & & & & & \\
\hline$u=.186$ & 0.913 & 0.836 & 0.242 & 0.328 & 0.118 & -0.018 \\
\hline & & & & & & \\
\hline $\begin{array}{c}\text { Individual } \\
\text { characteristics }\end{array}$ & & & & & & \\
\hline age=50 & 0.999 & 0.684 & 0.498 & 0.171 & 0.094 & -0.046 \\
\hline exp=20.2 & 0.894 & 0.924 & 0.193 & 0.421 & 0.152 & 0.012 \\
\hline dis=0.65 & 2.083 & 0.066 & 1.000 & 0.000 & 0.000 & -0.140 \\
\hline
\end{tabular}




\begin{tabular}{|c|c|c|c|c|c|c|}
\hline $\begin{array}{c}\text { Policy } \\
\text { parameters }\end{array}$ & & & & & & \\
\hline$\tau=0.25$ & 0.995 & 0.690 & 0.485 & 0.177 & 0.097 & -0.043 \\
\hline$s=0.58$ & 0.875 & 0.980 & 0.153 & 0.480 & 0.159 & 0.019 \\
\hline$\alpha=0.75$ & 1.420 & 0.680 & 0.997 & 0.167 & 0.000 & -0.140 \\
\hline & & & & & & \\
\hline
\end{tabular}

\section{Empirical job search model}

\subsection{Database and sample selection}

The study will use the Continuous Sample of Working Lives ("Muestra Continua de Vidas Laborales", MCVL) which is a microeconomic dataset based on administrative records provided by the Spanish Social Security Administration. It contains a random sample of $4 \%$ of all the individuals who, at some point during 2010, had contributed to the social security system (either by working or being on an unemployment scheme) or had received a contributory pension. The random sample selected contains over one million people.

There is information available on the entire employment and pension history of the workers, including the exact duration of employment, unemployment and disability pension spells, and for each spell, several variables that describe the characteristics of the job or the unemployment/disability benefits. There is also some information on personal characteristics such as age, gender, nationality and level of education. The macroeconomic variables used to capture the economic business cycle are derived from the Spanish "Instituto Nacional de Estadistica".

We select an inflow sample of all individuals that started receiving partial disability benefits between 1996 and 2010 and we follow their disability pensions until they find a job or until they are censored. They are censored if they stop receiving disability benefits, because they reach year 2010 or if they move to total disability benefits $(2,880$ in our sample). They can stop receiving disability benefits for various reasons: because they reach 65 and are automatically transferred to old-age pensions, because they die (or disappear from the country) or because their health condition improves and they lose their disability benefits in one of the health checks made by the Social Security administration. ${ }^{13}$ The selected sample contains 31,197 spells for 27,150 partially disabled individuals, from which 17,236 are men and 9,914 are women. Part of the analysis is also done with the same sample but only including individuals below the age of 55. In this alternative sample, there are 17,944 spells for 14,980 individuals, 9,896 of which are men and 5,084 are women.

\subsection{Complementary log-log duration model}

Disabled individuals can find a job at any point in time so that moving from the situation of only receiving the disability benefits to a situation of receiving the benefits with a job occurs in continuous time. Therefore, we use a complementary log-log model in order to derive an estimate of the parameters describing the continuous time hazard of

\footnotetext{
${ }^{13}$ Only $0.8 \%$ of individuals in our sample stop receiving disability benefits due to death or improvement of their health condition.
} 
finding a job for disabled individuals, as it allows us to take into account the nature of our grouped duration time data ${ }^{14}$. The hazard rate is modelled under the proportional hazard assumption and takes the form (Jenkins, 2005):

$\theta(t, x)=\theta_{0}(t) e^{\beta^{\prime} x}=\theta_{0}(t) \lambda$

where $\beta^{\prime} x=\beta_{0}+\beta_{1} x_{1}+\beta_{2} x_{2}+\ldots \beta_{k} x_{k}$ and $\lambda=\exp \left(\beta^{\prime} x\right)$

If we apply the complementary log-log transformation with spell intervals of unit length, the discrete-time proportional hazard model (or clog-log model) can be rewritten as:

$h(j, x)=1-\exp \left[-\exp \left(\beta^{\prime} x+\gamma_{j}\right)\right]$

where the $\gamma_{j}{ }^{\prime} s$ represent the pattern of duration dependence in the interval hazard and the $\beta$ 's coefficients are the same as in the continuous time version of the model.

Estimates of both the $\beta$ 's and the $\gamma_{j}{ }^{\prime} s$ can be derived using interval-censored data (Jenkins, 2005).

In order to avoid imposing any restriction on the specification of the form of the baseline hazard, we characterize duration dependence non-parametrically and allow the parameters $\gamma_{j}$ to vary from interval to interval. Therefore, our model is a semiparametric clog-log model and takes the form:

$h(j, x)=\gamma_{2} d_{2}+\gamma_{3} d_{3}+\ldots . . \gamma_{15} d_{15}+\beta^{\prime} x$

where $\mathrm{d}_{1}, \mathrm{~d}_{2}, \mathrm{~d}_{3} \ldots \mathrm{d}_{15}$ are dummy variables corresponding to each year in the sample from 1996 until 2010 and $\mathrm{u}$ is the unobserved heterogeneity term.

The probability of finding a job for someone who is currently receiving partial disability benefits depends on a number of personal characteristics, the region where the individual lives, the amount of pension received as well as business cycle conditions at the local level.

Therefore, as independent variables we include in the model a dummy variable for female, the age at which the individual became disabled (and entered the sample), dummies for the seventeen Autonomous Communities in Spain and three dummy variables that describe the professional category of the individual in their last job before becoming disabled, which act as a proxy of the highest level of education completed. The first professional category includes labourers, the second category includes assistants and administrative workers and the third category includes individuals with a bachelor degree or higher. We also include the logarithm of the regulatory base used to compute the benefit amount.

\footnotetext{
${ }^{14}$ We have also estimated the other discrete time duration model, the logistic hazard regression model, and we have found very similar results to those obtained with the cloglog model presented in the text. Therefore, we chose to use the cloglog model because it is the model used for a discrete time representation of a continuous time underlying model.
} 
As the regulation for being granted the increase in benefits is defined in terms of age (55) and other characteristics that may have an effect on the probability of working, we use as an instrument a dummy variable that captures whether the individual is 55 years old in order to estimate the effect of the increase in the percentage of the regulatory base from $55 \%$ to $75 \%$ on employment. This increase is granted to $60 \%$ of individuals at the age of 55 and to $75 \%$ of individuals in our sample aged 58 years ${ }^{15}$.

Two more explanatory variables are included to capture the characteristics of the employment experience before becoming disabled; the number of employment spells and a dummy variable that captures whether the individual was self-employed in the last job before becoming disabled. We believe that the number of employment spells can capture part of the assimilation costs of disabled individuals as individuals that have more diverse work experience before becoming disabled can be expected to be more prepared to work in a different sector and a different firm.

We also add a dummy variable for whether the individual will move to total disability benefits at some point in our sample (will be censored) as we assume that, for these individuals, the level of disability is not constant and increases during the sample period. In order to control for the local labour market conditions, we assign to each individual in our sample the value of the unemployment rate corresponding to the autonomous community where he/she lives and to his/her gender in order to control for regional business cycle trends. We derive this macroeconomic information from the Spanish National Institute of Statistics. As we have mentioned above, the baseline hazard is modelled non-parametrically and so we include 14 dummy variables that capture duration dependence (we exclude the first and include the constant in the model).

Finally, as it has been documented in the literature that the presence of unobserved factors makes it impossible to distinguish the selection effect from duration dependence and may lead to biased results, we control for unobserved heterogeneity in order to get unbiased coefficients. We assume a normal distribution for unobserved heterogeneity and estimate the model by maximum likelihood. ${ }^{16}$ In the theoretical model presented in section 3, this heterogeneity is captured by assuming that home productivity differs across disabled individuals.

\subsection{Empirical Hazard Rates}

If we take a look at the empirical hazard rates derived from our sample, we can already see the shape of duration dependence for duration in partial disability benefits until the individual finds a job. The empirical hazard for a given number of months is calculated as the total number of exits from receiving only partial disability to receiving disability plus a job in each year divided by the population on partial disability benefits at the beginning of that year. This summarizes the sample's probability of finding a job at each particular point in time.

\footnotetext{
${ }^{15} \mathrm{We}$ also report the results of a model that uses the percentage $(55 / 75 \%)$ of the regulatory base instead of the instrumental variable (older than 55) and the results and predictions are almost the same.

${ }^{16}$ We have also estimated the model without accounting for unobserved heterogeneity and the results do not change substantially.
} 
Figure 3 shows the interval hazard rates from partial disability into partial disability plus a job for the whole sample and for the sample restricted to the age of 55 or less. As can be seen, both plots show a maximum value for the hazard rate in the first couple of periods and a decreasing path for the remaining periods. Therefore, most of the individuals in our sample find a job within the first 2-3 years of becoming disabled. The two lines show a similar evolution, although the hazard is greater when we restrict the sample to include only the younger group of individuals.

Figure 3. Interval hazard rate. Complete sample and less than 55 years old.

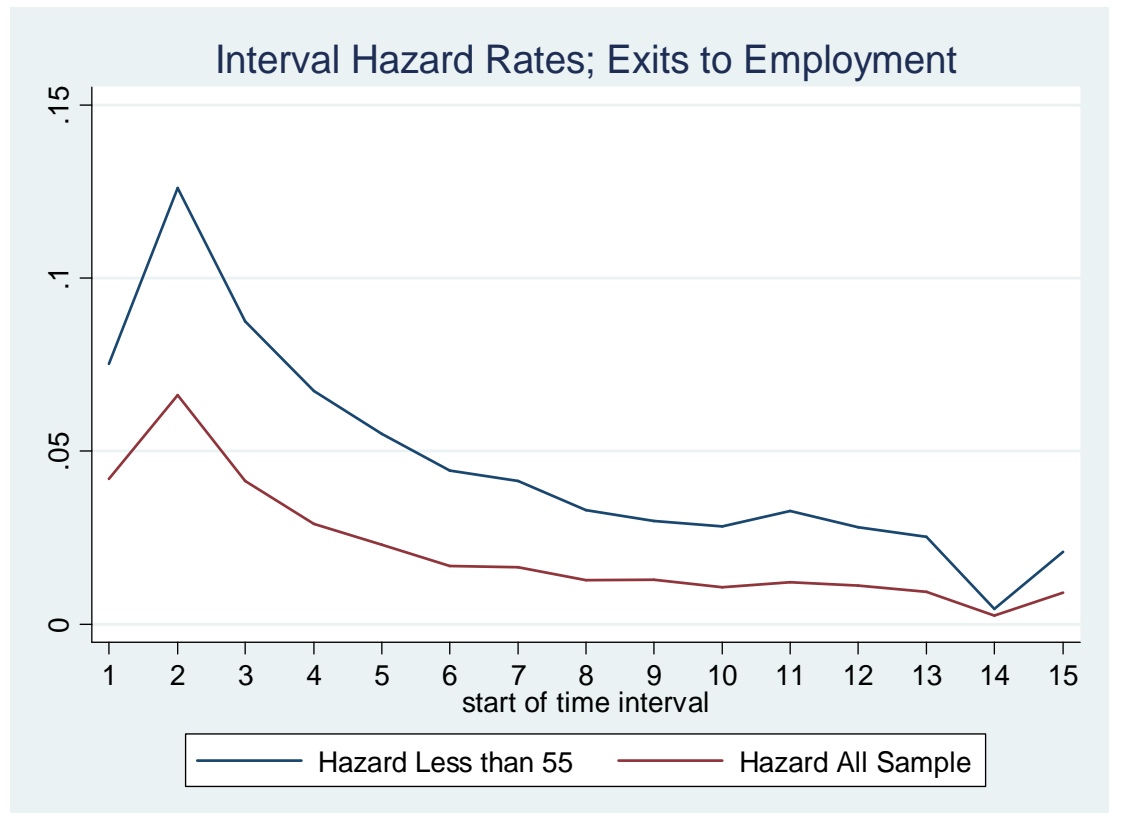

\section{Estimation Results}

Table A1 of the appendix reports the results of the complementary log-log model for exits from only receiving partial disability benefits to receiving the benefits plus a job. This can be interpreted as the job finding rate for partially disabled individuals. We confirm the presence of unobserved heterogeneity as reported by the likelihood ratio test at the end of table A1.

All the variables describing individual characteristics have the expected sign; the hazard of finding a job is lower for females, for individuals who become disabled at older ages, for individuals whose disability is worsening and will eventually move to total disability benefits and for individuals who were self-employed in their last job before becoming disabled and probably have greater difficulties assimilating into another job. As suspected, individuals with a higher number of employment spells before the onset of their disability have higher chances of finding a job as they have lower assimilation costs.

On the other hand, assistants and administrative workers exhibit a higher hazard rate of finding a job than labourers and individuals with a bachelor degree and disabled individuals that live in the Canary Islands, Cantabria and Galicia have the lowest hazard rates of finding a job in Spain. Not surprisingly, local labour market conditions play an important role in determining job finding rates for disabled individuals as shown by the 
negative and very significant coefficient that captures the effect of local unemployment rates. With respect to the amount of the disability pension, we note that the higher the regulatory base, the lower the hazard rate of finding a job and the coefficient is highly significant. Finally, the dummy variable for being older than 55 which we use as an instrument for receiving the increase in benefits is also negative and highly significant, as expected ${ }^{17}$. In the next section, we will measure the extent to which each of these covariates has an effect on the probability of finding a job for disabled individuals in our sample.

5.1. Comparing predictions of the theoretical job search model and the empirical hazard model

Table 3 compares the predicted hazard and job finding rates of the theoretical and the empirical model when we change some of the covariates of interest. All the predictions in the empirical model are performed after the estimation of the clog-log model for the sample of individuals under 55, so we are comparing a similar individual to the theoretical model. An exception is the effect of the increase in the percentage of the pension received that is predicted after the estimation of the clog-log model for the entire sample. As $77 \%$ of the individuals aged 55 or more in our sample receive an increase from $55 \%$ to $75 \%$ in the percentage of the regulatory base, we use the entire sample in order to include these individuals and be able to compare the prediction of the theoretical model to what happens in reality.

Table 3. Predicted results for comparison theoretical vs. empirical model: hazard rate in first year

\begin{tabular}{|c|c|c|c|c|}
\hline Scenario & $\begin{array}{c}\text { Predicted } \\
\text { Hazard Rate } \\
\text { Empirical } \\
\text { Model } \\
\end{array}$ & $\begin{array}{l}\text { Difference } \\
\text { Empirical } \\
\text { Model }\end{array}$ & $\begin{array}{c}\text { Predicted Job } \\
\text { Finding Rate } \\
\text { Theoretical } \\
\text { Model }\end{array}$ & $\begin{array}{c}\text { Difference } \\
\text { Theoretical } \\
\text { Model }\end{array}$ \\
\hline \multicolumn{5}{|l|}{$\begin{array}{l}\text { Employment Spells } \\
\text { Before Disability }\end{array}$} \\
\hline $\exp =19.2$ & 0.173 & \multirow[t]{2}{*}{0.002} & 0.140 & \multirow[t]{2}{*}{0.012} \\
\hline exp $=20.2$ & 0.175 & & 0.152 & \\
\hline \multicolumn{5}{|l|}{$\begin{array}{l}\text { Macroeconomic } \\
\text { conditions }\end{array}$} \\
\hline$u^{*}=.136$ & 0.161 & \multirow[t]{2}{*}{-0.027} & 0.140 & \multirow[t]{2}{*}{-0.022} \\
\hline$u^{*}=.186$ & 0.134 & & 0.118 & \\
\hline \multicolumn{5}{|l|}{$\begin{array}{c}\text { Individual } \\
\text { characteristics }\end{array}$} \\
\hline$a g e=44$ & 0.126 & \multirow[t]{2}{*}{-0.038} & 0.140 & \multirow[t]{2}{*}{-0.046} \\
\hline age $=50$ & 0.088 & & 0.094 & \\
\hline & & & & \\
\hline
\end{tabular}

${ }^{17}$ Of course, in the model in which we only include individuals under 55 years, we exclude the dummy for age older than 55 (model 2). 


\begin{tabular}{|c|c|c|c|c|}
\hline$d i s=0.50$ & 0.169 & \multirow[t]{2}{*}{-0.113} & 0.140 & \multirow[t]{2}{*}{-0.140} \\
\hline$d i s=0.65$ & 0.056 & & 0.000 & \\
\hline \multicolumn{5}{|l|}{ Policy parameters } \\
\hline$\alpha_{I}=\alpha_{U}=\alpha_{L}=0.55$ & 0.154 & \multirow{2}{*}{-0.135} & 0.140 & \multirow{2}{*}{-0.140} \\
\hline $\begin{array}{c}\alpha_{I}=\alpha_{U}=0.75 \\
\alpha_{L}=0.55\end{array}$ & 0.019 & & 0.000 & \\
\hline$\tau=0.15$ & \multirow[t]{2}{*}{ Not Available } & \multirow[t]{2}{*}{ Not Available } & 0.140 & \\
\hline$\tau=0.20$ & & & 0.122 & -0.018 \\
\hline$s=0.48$ & \multirow[t]{2}{*}{ Not Available } & \multirow[t]{2}{*}{ Not Available } & 0.140 & \\
\hline$s=0.58$ & & & 0.159 & 0.019 \\
\hline
\end{tabular}

We begin by discussing the effect of an increase in the unemployment rate by 5 points, from the mean of the sample 13.6, to 18.6. We can see that the empirical model predicts a decrease in the hazard rate of finding a job from 0.161 to 0.134 and the theoretical model also predicts a decrease from 0.140 to 0.118 . That is, the two models predict a decrease in the job finding rate of a very similar magnitude, -0.027 and -0.022 . We obtain a similar result when we modify the age at which the individual starts receiving disability benefits by six years, from the mean of the sample 44, to 50 . While the empirical model predicts a drop in the hazard rate of -0.038 , the theoretical model predicts a drop of -0.046 , again very similar results for the two models.

The size of the effect is somewhat different between the two models when we change the professional experience accumulated during the years prior to joining the disability rolls. The empirical model predicts an increase of 0.002 in the hazard of finding a job when we increase the number of employment spells before being disabled from 19.2 to 20.2 (a very small increase). For the same increase in employment spells, the theoretical model predicts a slightly higher increase in the probability of finding a job of 0.012 .

Another of the variables of interest is the level of disability. This variable is easily modified in the theoretical model from 0.50 to 0.65 and shows a large negative effect of the job finding rate, which changes from 0.140 to zero. As we do not have the exact information on the level of disability of the individuals included in our sample, in the empirical model we include a dummy variable which is 1 if the individual will eventually be re-classified from partially to totally disabled. This change is granted by a team of medical and administrative workers and entails an increase in the amount of disability benefits received (as the percentage of the regulatory base increases from 55\% to $100 \%$ ). Therefore, we assume that if the individual will eventually be moved to total disability, it means that his/her level of disability is not constant but increases during his/her stay in the partial disability system. Note that once the individual is granted total disability benefits, he/she appears as censored in our database. When we predict the change in the hazard rate of finding a job for this group of individuals that will eventually move to total disability, we find that the hazard rate is reduced by 0.113 which is a very similar result to the one obtained in the theoretical model (a reduction of $0.140){ }^{18}$

\footnotetext{
${ }^{18} \mathrm{We}$ are aware that the level of disability is not an exogenous variable but we do not make any causality claim. We are only interested in observing the change in employment for different levels of disability.
} 
Figure 4. Predicted hazard rate of the increase in disability benefits

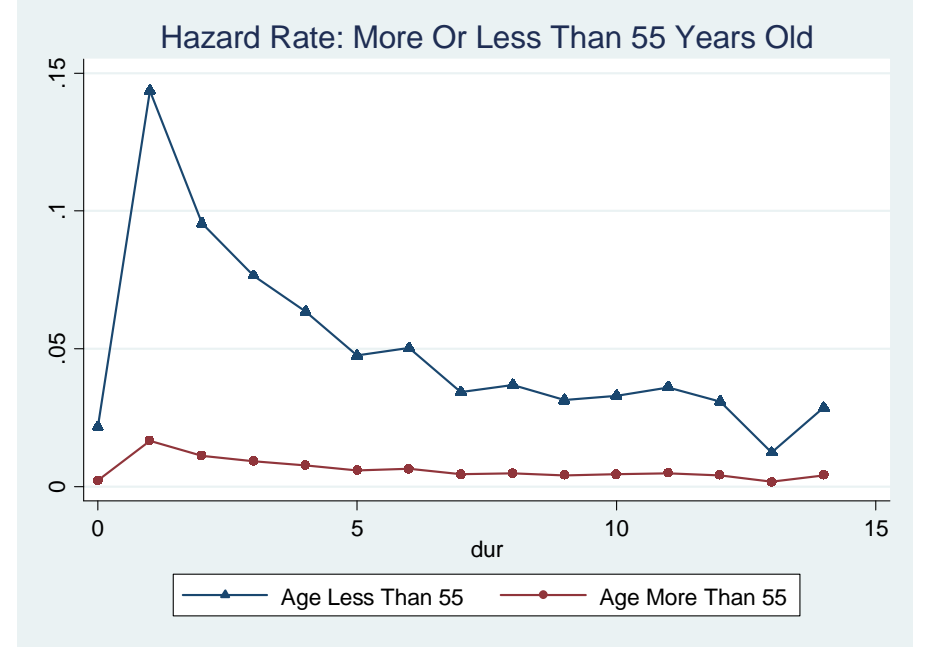

With respect to the policy parameters, we can perform three exercises with the theoretical model but we can only compare the results of one of them to the empirical model. That is, the increase in the percentage of the regulatory base from $55 \%$ to $75 \%$. The two models give very similar predictions with respect to this variable. In the theoretical model, we estimate the effect of receiving the increase in disability benefits if the individual is non-employed while the percentage of the regulatory base is keep at the $55 \%$ level if the individual is employed, as the legislation states that the $20 \%$ increase will be suspended if the individual works. We see that this increase reduces the job finding rate for disabled individuals to 0 as the reservation wage increases from 0.918 to 1.420 . In the empirical model, as the increase in benefits is granted to individuals who are older than 55 and, "whose lack of education/training and the social and labour market conditions of the region where they live make it difficult for them to find a job", we have reason to believe that the variable that captures the percentage of the pension may be endogenous to the employment status so we use as an instrument a dummy variable that captures whether the individual is aged more or less than $55^{19}$. The prediction also gives a large decrease in the hazard rate of finding a job from 0.154 to 0.019 for individuals that receive the increase in benefits in our sample. That is, in the theoretical model the probability of finding a job decreases by 0.140 whereas in the empirical model it decreases by 0.135 . As the legislation states that if you are receiving the $75 \%$ and begin working the $20 \%$ increase will be suspended until the individual stops working, this last exercise allows us to show the presence of a large substitution effect to stop working for disabled individuals aged 55 or more (which can be observed in figure 4).

In order to make sure that the drop in the job finding rate is not due to other reasons, we test for two other potential causes that could explain the drop in employment. That is, we confirm that there is no anticipation effect before reaching age 55 and we check that the drop in employment is not attributable to an increase in the personal income tax rate as a result of the increment in disability benefits. Therefore, if that is the case, individuals can have an incentive to stop working in order to avoid being changed to a

\footnotetext{
${ }^{19}$ We have also estimated the same model but including the percentage of the regulatory base received (either 55 or $75 \%$ ) and we estimate a drop in the hazard rate of finding a job from 0.144 to 0.012 and an almost identical hazard rate to that plotted in figure 4.
} 
higher marginal tax rate. We test for this possibility in both the theoretical and the empirical models. In the first case, the simulated decrease of only 1.8 percentage points in the job finding rate as a consequence of an increase of 5 percentage points in the average income tax (from $15 \%$ to $20 \%$ in Table 3 ) shows a relatively low sensitivity of labor supply to the tax channel ${ }^{20}$. This cannot explain the drop of 13.5 percentage points in the job finding rate reported above when we increase the level of benefits. Moreover, we empirically compare the incomes (benefit plus wage) before and after receiving the increase and we find that only $1 \%$ of the individuals do move from one marginal tax rate to a higher one (we consider the marginal tax schedule for each year from 1996 until 2010). As this is a very small proportion, we conclude that there is no significant substitution effect due to increases in the marginal tax rates.

The belief that not working would increase the probability of being granted the increment in benefits may also be an explanation for the fall in the job finding rate. In this case, we should expect a fall in job search intensity and, therefore, a major reduction in the hazard rate of finding a job during the year before receiving the increase in benefits. Figure 5 shows, however, that a major drop in the job finding rate only takes place after 55 years of age, which is the threshold age for having the increase in disability benefits. It is important to emphasize that the percentage of disabled individuals receiving the increment rises from $1.1 \%$ before 55 years to $66.5 \%$ and $73.3 \%$ at 55 and 56, respectively. This piece of evidence minimizes the possibility of an anticipation effect related to the belief that being employed at 55 years of age can be a risk of not being granted the adjustment in the pension ${ }^{21}$.

Figure 5. Predicted job finding hazard rates by age

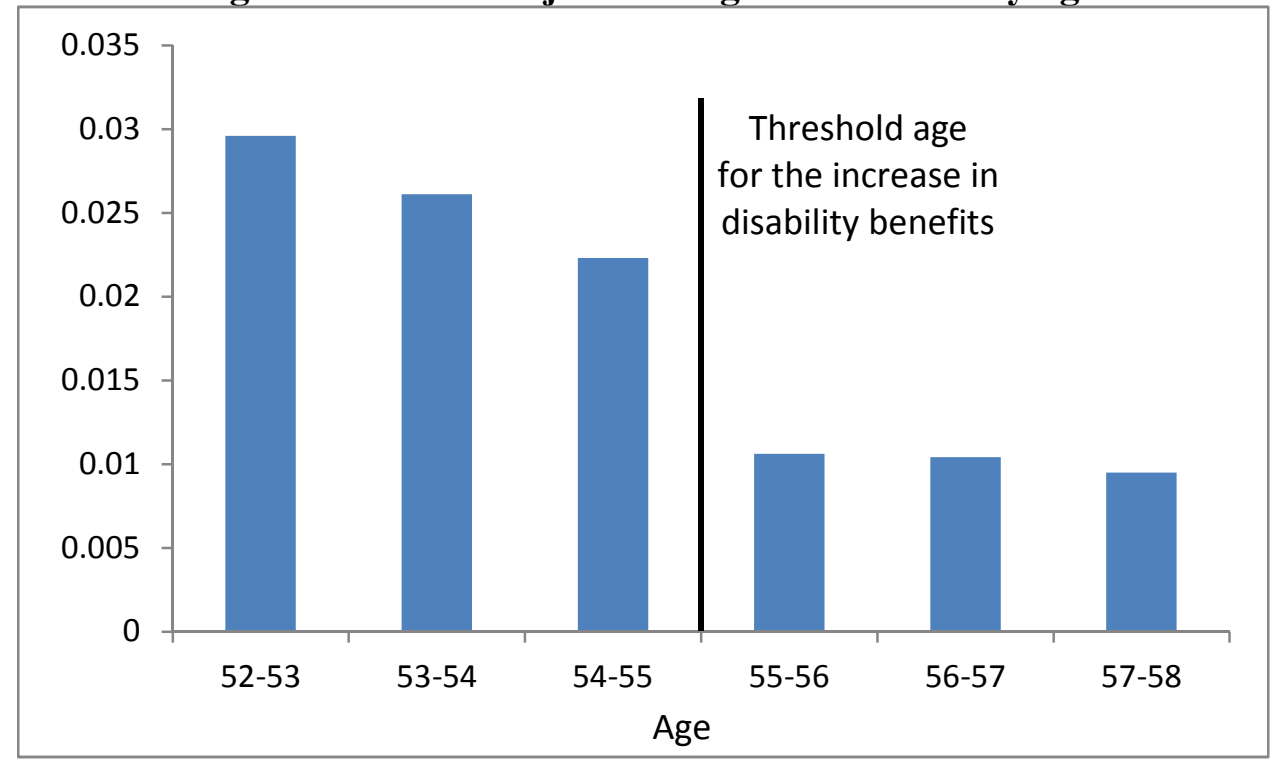

Finally, we perform a policy simulation experiment to test whether the strong substitution effect found as a result of the increase in the benefits and the inability to combine it with a job would disappear if the working restriction would be abolished. Therefore, we allow $\alpha$ being $75 \%$ even if the individual works while receiving the

\footnotetext{
${ }^{20}$ This increase by 5 percentage points in $\tau$ is consistent with the marginal tax schedule in Spain.

${ }^{21}$ Figure 5 is done including only individuals that are in the disability system before turning 55 years old. The reason for this is the fact that the increase in the benefits induces an inflow effect to the system as reported in Olivier and Vall Castello, 2012.
} 
increase in the benefits. In this case, as showed in the simulations in table 2, the job finding probability is also reduced to practically zero. Therefore, even if we abolished the conditionality and the working restrictions of the increase in the benefits so that there is no substitution effect in place, we would still have a strong income effect that would keep the job finding probability to zero.

\section{Conclusions}

Unlike other disability systems in developed economies, the Spanish system allows partially disabled individuals to work while receiving disability benefits. The puzzle is, however, that employment rates for this group of partially disabled individuals are very low. Therefore, in an attempt to understand the reasons behind this low employment rate of disabled individuals in Spain, in this paper we have presented a theoretical job search model for partially disabled individuals as well as an empirical application to the Spanish disability system. More specifically, in the empirical part we estimate a complementary log-log duration model and perform some predictions after the estimation that we compare to the simulations obtained by the theoretical model.

We find that the predicted change in the hazard and job finding rates of the theoretical and empirical models are very similar for most of the variables analysed. According to both models, the probability of finding a job falls with the level of disability; the age at which the individual starts receiving disability benefits and; the increase in the local unemployment rate.

In the partial disability system, individuals aged 55 or more and that have low prospects of finding a job can receive an increase in the level of disability benefits from $55 \%$ to $75 \%$ of the regulatory base. However, the legislation also states that if the individual begins working while receiving the $75 \%$, the $20 \%$ increase will be suspended until he stops working. Therefore, tis rule allows us to estimate the employment effects of the increase in the benefits with both the empirical and the theoretical model. In the empirical part, we use age as an instrumental variable for receiving the increase in benefits and we observe that the hazard rate of finding a job decreases by 13.5 percentage points for individuals that receive the increase. This drop in the job finding rate can be explained by: (i) a substitution effect as the increase is suspended if the individual works; (ii) a substitution effect due to the possibility of an increment in the personal income tax rate as the total income of the individual increases, or; (iii) an anticipation effect generated by the belief that not working would maximize the chances of being granted the increase in benefits. Therefore, we use the theoretical job search model to simulate the effect of receiving the increase in benefits from $55 \%$ to $75 \%$ of the regulatory base when the individual is not working which will allow us to uncover the channel behind the observed drop in employment. Our results show that the job finding rate is reduced for disabled individuals by 14 percentage points and so we confirm the existence of a large substitution effect which explains the entire drop in the job finding rate observed in the empirical model. We perform some robustness checks and we are able to rule out both the existence of a substitution effect due to marginal taxation as well as the existence of any other anticipation effect due to a perceived conditionality of the increase in benefits.

From a policy perspective, the aim of the increase in disability benefits is to provide income insurance to workers that face a double discrimination in the labor market: 
being disabled and old. However, we observe that, in practice, there is a secondary unforeseen effect of reducing the hazard rate of finding a job. Therefore, we further perform a policy simulation experiment with the theoretical model to assess the employment effects of abolishing the working restriction of the $20 \%$ increase in the benefits. Our results show that even when the increase is not dependent on the employment situation of the individual, the job finding probability is reduced to virtually zero due to the presence of a strong income effect.

Therefore, the advantage of the Spanish disability system of allowing the combination of the receipt of benefits with a job disappears due to the presence of a large substitution or income effect that generates disincentives to work independently on whether the increase is conditional or not on the working status of the disabled individual. Of course, the two effects are different, however, from a welfare point of view.

This is an important finding as most of the developed economies that have an "all-ornothing" system in which you automatically lose the benefits when you work are advocating for a change to a partial system that allows a combination (of part) of the benefits with a job, which is exactly the Spanish case. Therefore, we conclude by highlighting that, even in partial disability systems, there is a need to take into account all the rules in disability programs that may create disincentives to work. Consequently, if the policy maker's main aim is to increase disabled individuals' employment rates, this type of disincentive effects should be removed from the legislation.

Finally, this job search model could also serve as the basis to explain other income effects that have been empirically documented in disability programs in other countries, particularly the drops in labor supply found by Autor et al. (2011) and Boyle and Lahey (2010) when analysing the Veterans Administration's Disability Compensation program in the USA. 


\section{Bibliography}

Addison J, Centeno M, Portugal P. Key Elasticities in Job Search Theory: International Evidence. IZA Discussion Paper Series No.1314; 2004.

Autor DH, Duggan MG. The Growth in the Social Security Disability Role: A Fiscal Crisis Unfolding. Journal of Economic Perspectives 2006; 20; 71-96.

Autor DH, Duggan MG. Distinguishing Income from Substitution Effect in Disability Insurance. American Economic Review Papers and Proceedings 2007; 97; 119-124.

Autor DH, Duggan MG. The Effect of Transfer Income on Labor Force Participation and Enrollment in Federal Benefits Programs: Evidence from the Veterans Disability Compensation Program. A Report to the Social Security Administration. Unpublished; 2008.

Autor DH, Duggan MG, Lyle DS. Battle Scars? The Puzzling Decline in Employment and Rise in Disability Receipt Among Vietnam Era Veterans. American Economic Review Papers and Proceedings 2011; 101(3); 339-44.

Benitez-Silva H, Buchinsky M, Rust J. Using a Life Cycle Model to Predict Induced Entry Effects of a $\$ 1$ for $\$ 2$ Benefit Offset in the SSDI Program. Forthcoming in the Journal of Policy Analysis and Management 2012.

Benítez-Silva H, Heiland F. Early claiming of Social Security Benefits and Labor Supply Behavior of Older Americans. Applied Economics 2008; 40(23); 2969-2985.

Benítez-Silva H, Heiland F. The Social Security Earnings Test and Work Incentives. Journal of Policy Analysis and Management 2007; 26(3); 527-555.

Boyle MA, Lahey JN. Health Insurance and the Labor Supply Decisions of Older Workers: Evidence from a U.S. Department of Veterans Affairs Expansion. Journal of Public Economics 2010; 94; 467-478.

Buddelmeyer H. Re-employment Dynamics of Disabled Workers. IZA Discussion Paper Series No.269; 2001.

Burkhauser RV, Daly MC. The Decline Work and Welfare of People with Disabilities: What went wrong and a strategy for change. Washington DC; American Enterprise Institute Press; 2011.

Jenkins S. Survival Analysis. Manuscript; 2005.

Maestas N, Yin N. The Labor Supply Effects of Disability Insurance Work Disincentive: Evidence from the Automatic Conversion to Retirement Benefits at Full Retirement Age. Michigan Retirement Research Center Working Paper 194; 2008.

Marie O, Vall Castello J. Measuring the (Income) Effect of Disability Insurance Generosity on Labour Market Participation. Journal of Public Economics 2012; 96(1-2); 198-210. 
Petrongolo B, Pissarides CA. Looking into the Black Box: A Survey of the Matching Function. Journal of Economic Literature 2001; 39; 390-431

Pissarides C. Equilibrium Unemployment Theory, 2nd edition; Cambridge, Mass: MIT Press; 2000.

Postel-Vinay F, Robin JM. Equilibrium Wage Dispersion with Worker and Employer Heterogeneity. Econometrica 2002; 70(6); 2295-2350.

OECD. Transforming Disability into Ability: Policies to Promote Work and Income Security for Disabled People. OECD, Paris; 2003.

OECD. Sickness, Disability and Work: Breaking the Barriers - Vol. 2: Australia, Luxembourg, Spain and the United Kingdom. OECD, Paris; 2007.

Vall-Castello J. Promoting Employment of Disabled Women in Spain: Evaluating a Policy. Labour Economics 2012; 19(1); 82-91.

Yin N. Partial Benefits in the Social Security Disability Insurance Program: A Policy Alternative to Foster Work among the Disabled; 2010.

Yin N, Benitez-Silva H. An Empirical Study of the Effects of Social Security Reforms on Benefit Claiming Behavior and Receipt Using Public-Use Administrative Micro Data. The Social Security Bulletin 2009; 69(3); 77-95. 


\section{Appendix}

Table A1: Complementary log-log model: Probability parcial+work

\begin{tabular}{|c|c|c|}
\hline VARIABLES & $\begin{array}{c}\text { Model1 } \\
\text { Employment }\end{array}$ & $\begin{array}{c}\text { Model2 } \\
\text { Employment }\end{array}$ \\
\hline Duration2 & $\begin{array}{l}1.196 * * * \\
(0.0422)\end{array}$ & $\begin{array}{c}1.273 * * * \\
(0.0458)\end{array}$ \\
\hline Duration3 & $\begin{array}{c}0.724 * * * \\
(0.0543)\end{array}$ & $\begin{array}{c}0.847 * * * \\
(0.0596)\end{array}$ \\
\hline Duration4 & $\begin{array}{l}0.394 * * * \\
(0.0669)\end{array}$ & $\begin{array}{l}0.564 * * * \\
(0.0734)\end{array}$ \\
\hline Duration5 & $\begin{array}{l}0.163 * * \\
(0.0794)\end{array}$ & $\begin{array}{c}0.338 * * * \\
(0.0877)\end{array}$ \\
\hline Duration6 & $\begin{array}{l}-0.194^{*} \\
(0.0995)\end{array}$ & $\begin{array}{l}0.0538 \\
(0.108)\end{array}$ \\
\hline Duration7 & $\begin{array}{c}-0.224^{* *} \\
(0.112)\end{array}$ & $\begin{array}{l}-0.0441 \\
(0.125)\end{array}$ \\
\hline Duration8 & $\begin{array}{c}-0.543 * * * \\
(0.141)\end{array}$ & $\begin{array}{c}-0.330 * * \\
(0.157)\end{array}$ \\
\hline Duration9 & $\begin{array}{c}-0.442 * * * \\
(0.151)\end{array}$ & $\begin{array}{l}-0.346^{*} \\
(0.178)\end{array}$ \\
\hline Duration10 & $\begin{array}{c}-0.623 * * * \\
(0.184)\end{array}$ & $\begin{array}{c}-0.430 * * \\
(0.208)\end{array}$ \\
\hline Duration 11 & $\begin{array}{c}-0.516^{* *} \\
(0.202)\end{array}$ & $\begin{array}{l}-0.322 \\
(0.230)\end{array}$ \\
\hline Duration 12 & $\begin{array}{c}-0.487 * * \\
(0.238)\end{array}$ & $\begin{array}{l}-0.336 \\
(0.278)\end{array}$ \\
\hline Duration13 & $\begin{array}{c}-0.657 * * \\
(0.324)\end{array}$ & $\begin{array}{l}-0.545 \\
(0.387)\end{array}$ \\
\hline Duration14 & $\begin{array}{c}-1.735^{* *} \\
(0.711)\end{array}$ & $\begin{array}{c}-1.959 * \\
(1.004)\end{array}$ \\
\hline Duration15 & $\begin{array}{l}-0.441 \\
(0.584)\end{array}$ & $\begin{array}{l}-0.370 \\
(0.715)\end{array}$ \\
\hline Female & $\begin{array}{c}-0.619 * * * \\
(0.0464)\end{array}$ & $\begin{array}{c}-0.630 * * * \\
(0.0501)\end{array}$ \\
\hline Age Disability & $\begin{array}{c}-0.0621 * * * \\
(0.00232)\end{array}$ & $\begin{array}{c}-0.0585^{* * *} * \\
(0.00235)\end{array}$ \\
\hline Total Disability & $\begin{array}{c}-0.991 * * * \\
(0.0695)\end{array}$ & $\begin{array}{c}-1.046 * * * \\
(0.0758)\end{array}$ \\
\hline Professional Category $=2$ & $\begin{array}{l}0.121 * * \\
(0.0507)\end{array}$ & $\begin{array}{l}0.109 * * \\
(0.0546)\end{array}$ \\
\hline Professional Category $=3$ & $\begin{array}{c}-0.0701 \\
(0.104)\end{array}$ & $\begin{array}{c}-0.271 * * \\
(0.124)\end{array}$ \\
\hline Ln(Regulatory Base) & $\begin{array}{c}-0.152 * * * \\
(0.0384)\end{array}$ & $\begin{array}{l}-0.102 * * \\
(0.0416)\end{array}$ \\
\hline Age More 55 & $\begin{array}{c}-1.098 * * * \\
(0.0580)\end{array}$ & \\
\hline Self-Employed Before & $-0.183 * * *$ & $-0.242 * * *$ \\
\hline
\end{tabular}




\begin{tabular}{|c|c|c|}
\hline \multicolumn{3}{|l|}{ Disabled } \\
\hline & $(0.0518)$ & $(0.0569)$ \\
\hline \multirow{2}{*}{$\begin{array}{l}\text { Employment Spells Before } \\
\text { Disabled }\end{array}$} & $0.00997 * * *$ & $0.00951 * * *$ \\
\hline & $(0.00102)$ & $(0.00112)$ \\
\hline \multirow[t]{2}{*}{ Andalucia } & 0.0489 & 0.0568 \\
\hline & $(0.0751)$ & $(0.0815)$ \\
\hline \multirow[t]{2}{*}{ Aragon } & 0.101 & 0.193 \\
\hline & $(0.112)$ & $(0.119)$ \\
\hline \multirow[t]{2}{*}{ Asturias } & -0.0936 & -0.133 \\
\hline & $(0.107)$ & $(0.115)$ \\
\hline \multirow[t]{2}{*}{ Balearic Is } & 0.178 & 0.179 \\
\hline & $(0.109)$ & $(0.118)$ \\
\hline \multirow[t]{2}{*}{ Canary Is } & $-0.221 * *$ & $-0.216^{*}$ \\
\hline & $(0.108)$ & $(0.116)$ \\
\hline \multirow[t]{2}{*}{ Cantabria } & $-0.630 * * *$ & $-0.572 * * *$ \\
\hline & $(0.173)$ & $(0.189)$ \\
\hline \multirow[t]{2}{*}{ Castile Leon } & -0.0688 & -0.0256 \\
\hline & $(0.0938)$ & $(0.101)$ \\
\hline \multirow[t]{2}{*}{ Castile Mancha } & 0.0561 & 0.0700 \\
\hline & $(0.0947)$ & $(0.102)$ \\
\hline \multirow[t]{2}{*}{ Catalonia } & -0.0261 & 0.0135 \\
\hline & $(0.0724)$ & $(0.0786)$ \\
\hline \multirow[t]{2}{*}{ Valencia } & -0.00192 & 0.0213 \\
\hline & $(0.0784)$ & $(0.0851)$ \\
\hline \multirow[t]{2}{*}{ Extremadura } & 0.0463 & 0.0306 \\
\hline & $(0.118)$ & $(0.128)$ \\
\hline \multirow[t]{2}{*}{ Galicia } & $-0.478 * * *$ & $-0.418 * * *$ \\
\hline & $(0.0890)$ & $(0.0952)$ \\
\hline \multirow[t]{2}{*}{ Murcia } & 0.0546 & 0.158 \\
\hline & $(0.102)$ & $(0.107)$ \\
\hline \multirow[t]{2}{*}{ Navarra } & -0.0519 & 0.0731 \\
\hline & $(0.161)$ & $(0.173)$ \\
\hline \multirow[t]{2}{*}{ Basque C } & $-0.219 * *$ & -0.0870 \\
\hline & $(0.101)$ & $(0.108)$ \\
\hline \multirow[t]{2}{*}{ Rioja } & 0.0968 & 0.221 \\
\hline & $(0.189)$ & $(0.196)$ \\
\hline \multirow[t]{2}{*}{ Unemployment Rate CCAA } & $-0.0396 * * *$ & $-0.0398 * * *$ \\
\hline & $(0.00313)$ & $(0.00336)$ \\
\hline \multicolumn{3}{|l|}{ Professional Category $(1,2,3)$} \\
\hline \multirow[t]{2}{*}{ Constant } & $1.922 * * *$ & $1.136 * *$ \\
\hline & $(0.441)$ & $(0.476)$ \\
\hline Rho & $0.1881 * * *$ & $0.1740 * * *$ \\
\hline (likelihood-ratio test of rho $=0$ ) & $(0.0236)$ & $(0.0262)$ \\
\hline Observations & 102,762 & 48,624 \\
\hline Number Individuals & 19,231 & 11,306 \\
\hline
\end{tabular}

